\title{
First language transfer in second language acquisition as a cause for error-making in translations
}

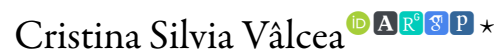 \\ Faculty of Letters, "Transilvania" University of Brașov, Bd. Eroilor 29, 500036 Braşov, Romania
}

Article info
History:
Received March 8, 2020
Accepted April 25, 2020
Published June 10, 2020
Key words:
linguistic transfer
interference
second language acquisition

\section{Article info}

History:

Received March 8, 2020

Accepted April 25, 2020

Key words:

inguistic transfe

second language acquisition

\begin{abstract}
Starting from Lord (2008), who claims that 'many researchers study the effects of L2 on mother tongue, but few researchers analyze the effects of mother tongue on L2', I have decided to analyze in this piece of research the errors produced by Romanian students when translating tense-based sentences from Romanian into English, in order to establish whether or not the errors are produced as a consequence of the transfer of the grammar knowledge of the students from their mother tongue on L2 or, why not, if the errors occur as a result of other factors. It is often claimed that, when students transfer grammar knowledge from L1 into L2, errors may occur due to the structural grammar differences between the source and the target language. From this point of view, important differences between the Romanian and the English verb system (the aspect, the temporal sequentiality as reflected in posteriority, simultaneity and anteriority) might reveal in the end that Romanian students that learn English as a foreign language transfer in English structures and forms from Romanian, which inevitably leads to errors. When analyzing the reasons that lead to error making when learning a foreign language, linguists, didacticians and methodologists claim that the interference between the mother tongue (Romanian, in this case) and the newly learnt language (English) is an important source for making errors. Linguistic interference, also known as language transfer, refers to the transfer of linguistic features between languages, emphasizing the fact that the transfer can be either positive or negative. Positive linguistic transfer (target-like use of L2) is when the grammatical structure or element is the same in both languages and consequently, the produced outcome is correct. On the contrary, negative linguistic transfer (non-target-like use of L2) is when the grammatical structure is different from one language to the other and the outcome breaks the linguistic laws in the target language. The theoretical approach that deals with the analysis of the differences and similarities between languages is contrastive analysis which has demonstrated that when two languages are more distinct, the likelihood of greater negative transfer is all too possible. That implies that any two languages which have more similar grammatical rules would expectedly result in positive transfer. Contrastive analysis proves its usefulness especially in the teaching-learning process; firstly, the teacher must be aware of the differences between the students' first language and their L2 in order to help students overcome difficulties when learning a foreign language and to reduce the number of transfer errors that students might produce. Secondly, the students need to become themselves aware of these differences so that they make fully-informed linguistic decisions. Thus, this is a predictive method of knowing beforehand what might lead to errors when Romanian students translate from Romanian into English. Nevertheless, teaching should not be based on this comparative analysis as the only way of teaching students.
\end{abstract}

`Email address: cristina.valcea@unitbv.ro. 


\section{Aim of the research}

I have decided to analyze in this piece of research the errors produced by Romanian students when translating tense-based sentences from Romanian into English in order to establish whether or not the errors are produced as a consequence of the transfer of the grammar knowledge of the students from their mother tongue on L2. When students transfer grammar knowledge from L1 to L2 errors may occur due to the structural grammar differences between the source and the target languages. From this point of view, important differences between the Romanian and the English verb system (the aspect, the temporal sequentiality as reflected in posteriority, simultaneity and anteriority) might reveal in the end that Romanian students that learn English as a foreign language transfer in English structures and forms from Romanian, which might lead to errors.

\section{Literature review}

Learning a foreign language has been analyzed to the end of discovering the mechanisms and the instruments that contribute to learning a new language with all the resulting side effects, such as the interference between L1 and L2 which might result, depending on the grammatical compatibility between the languages, into a positive or a negative transfer. The linguistic transfer is positive when the grammatical structure or element is the same in both languages and consequently, the produced outcome is correct. Contrastingly, negative linguistic transfer is when the grammatical structure is different from one language to the other and the outcome breaks the linguistic laws in the target language.

Interference was coined for the first time in relation to the phenomenon of bilingualism by Weinreich (1953, p. 1), who defined interference as "those instances of deviation from the norms of either language which occur in the speech of bilinguals as a result of their familiarity with more than one language". Lado (1957, p. 1) evinces defining features of interference as the heavy reliance on L1 features when L1 and L2 share common features: "We assume that the student who comes in contact with a foreign language will find some features of it quite easy and others extremely difficult. Those elements that are similar to his native language will be simple for him, and those elements that are different will be difficult". Moreover, Lado (1957, p. 59) comes up with a theory which he names Contrastive Analysis Hypothesis (CAH) in which he alleges that learner difficulty when learning L2 can be easily predicted by 'an utterance-byutterance comparison' of the learner's L1 and L2. In other words, the more different the languages, the greater the difficulty of learning any L2. Similarly, the greater the similarity between L1 and L2, the higher the likelihood of actually learning any L2.

Linguistic schools have elaborated different theories likely to explain how languages are learnt, how the transfer takes place and how errors are made, based on various elements that contribute to learning.

One such approach, the behaviourist one (Cooter \& Reutzel, 2004), claims that at the basis of learning is imitation, as a simple repetition of a structure previously exposed to and now able to reproduce, which helps young learners take in many new structures by reproducing the adult verbal behaviour. The individual user is not perceived as adapting language to their own needs or as meaning creators; they are basically imitators that reproduce language structures without influencing language. Imitation is accompanied by rewards and practice to boost up independent linguistic behaviour. Yet, a shortcoming of this approach in relation to learning a foreign language is that it mostly applies to learning the maternal language, which makes it less suitable to the purpose of learning a foreign language.

Stemming from behaviourism, but developing in a divergent direction, associative learning is believed to represent "the ability of living organisms to perceive contingency relations between events in their environment. It is a fundamental component of adaptive behaviour as it allows anticipation of an event on the basis of another" (Jozefowiez, 2012, p. 17). Thus, according to associative learning, the acquisition of any L2 may be done by "statistical correlations between stimuli and/ or responses" (Schmidt, 2012, p. 85). It results that learning in general is a complex phenomenon that is based on associations, similarities, 
differences, predictions that help humans define phenomena not in isolation, but in connection to other elements. As for learning L2s, by applying the same principles, correlations, similarities and differences between L1 and any L2 do play an important role in the learning process. Another important contribution to associative learning is the one issued by Corder (1967, p. 165), who changes the perspective on errors which he no longer considers as indicators of learners' difficulties, but as an indication of difficulty, "a learner's active attempts at systematic development via intake" (Ellis, 1997, p. 187). Corder's concept of interlanguage illustrates the intermediate stage when learners build L2 knowledge on L1 and where all linguistic acquisitions are important for the learner who experiments with two linguistic systems, sometimes independently, sometimes jointly. An important issue that illustrates the difficulties that L2 learners confront with when learning English is the phenomenon of redundancy (Ellis, 1998, p. 179). He gives the example of the English verbal system where temporal reference is mainly and primarily indicated by temporal adverbials, but not only. Thus, the temporal adverbial cues, being introduced first, tend to overshadow any other cues that might indicate the temporal reference of a verb. Consequently, L2 learners, trained to identify the temporal adverbials, will ignore any other cues that might greatly contribute to the establishment of the tense and aspect to be used in certain situations.

The communicative approach to teaching and learning second languages has a different approach considering that interaction is the means and the goal of learning a second language. The communicative approach tries to impose the idea that all new second or foreign languages need to be learnt through the new languages themselves suggesting the total elimination of the mother tongue which is interpreted as an obstacle against the acquisition of any second language. Yet, Swan $(1985$, p. 85) criticizes the intentional elimination of $\mathrm{L} 1$ from the learning of $\mathrm{L} 2$ considering that it is only natural for learners to start from the assumption that both L1 and L2 have similar elements, which will prove right or not later on when they get deeper into the study of L2: "In fact, if we did not keep making correspondences between foreign language items and mother tongue items, we would never learn foreign languages at all.” Moreover, he claims that L1 and the interference between L1 and L2 should not be blamed for the errors that might appear in the learning process because, he alleges, it is the same mother tongue that guarantees to a great extent any success in the correct speaking of any L2: "Interlanguages notoriously contain errors which are caused by interference from the mother tongue; it is not always realized that a large proportion of the correct features in an interlanguage also contains a mother tongue element" (Swan, 1985, p. 85). Much later, Storch \& Wigglesworth (2003, p. 762) share Swan's idea by arguing that 'the use of the L1 may provide learners with additional cognitive support that allows them to analyse language and work at a higher level than would be possible were they restricted to sole use of their L2'. Yadav (2014) comes also in defence of L1 which, he considers, should be perceived as a resource that learners use consciously or unconsciously in order to organize the input data so that they could produce correct structures.

Contrarily, the cognitive approach (Achard \& Niemeier, 2004, p. 4) is highly interested in the language as it is used by the speakers with the variations that they bring along and, consequently, in the dynamics of the language. Unlike the behaviourist approach which predominantly refers to the learning of mother tongues, the cognitive approach, more encompassing in scope, addresses the learning of both mother and foreign languages focusing on the existing similarities and dissimilarities when learning languages. Secondly, the cognitive approach offers an explanation for the great variety of alternative structures to be found in language as a mirroring of the great construing capacity of the speakers of a language to represent one and the same event or fact (Langacker, 2008, p. 7).

When dealing with the issue of learning a foreign language, the cognitive approach acknowledges the competition existing between L1 and L2, as the speaker will always be tempted to retort to L1 when producing a discourse in L2. In fact, Achard \& Niemeier (2004, p. 6) claim that "in a developing L2 system, the target units are in direct competition with the native ones because they both represent alternative ways of construing the same reality." Though, apparently, cognitive linguistics admits as natural the support that learners seek in their L1 when dealing with the difficulties of L2, there are quite many didacticians that consider that a mistake. They actually claim that the more the learners rely on their L1, the more they will 
have an increased difficulty in learning their L2 and, even worse, the more the interference between L1 and L2 will increase. Yet, the cognitive linguists Achard \& Niemeier (2004) claim that between L1 and L2 there is a phenomenon of transfer fairly active from L1 into L2 and rather reduced, though possible, from $\mathrm{L} 2$ into L1. The reason for which L1 transfers grammatical data into L2 is "the accessibility and degree of automaticity attained in L1" (Waara, 2004, p. 52) when that degree is actually attained as in the case of adults.

A demonstration of the fact that learning one language is not independent from any other language that has already been learnt is the very existence of the phenomenon of blending. When both languages contribute to the discourse with some structures that the speaker is familiar with in either L1 or L2, then, according to Fauconnier (1997), the phenomenon of blending occurs which designates a new space created voluntarily (the speaker knows the distinct structures in both languages, but prefers to blend both languages) or involuntarily (the speaker is unaware of the structure in one of the languages and uses the one that is known). An example of blending between Romanian and English that occurs quite frequently in the Romanian corporate management and which is an illustration of L2 influencing L1 as English is the international language of corporate management in the following excerpt from a conversation:

"Crezi că face sens să forcastăm în continuare pe pipeline-ul deja existent, în care customizăm produsele de end-user?" (Adevărul, 4 feb. 2015, de Ioana Nicolescu [online])

"Do you think it makes sense to continue forecasting on the existing pipeline, where we customize the end-user products?" (my translation)

This blending between Romanian and English excessively used in corporations creates, as Fauconnier stated, a new space 'the romglais' which is a mixture of Romanian and English words and where the English words double words that Romanian has and that would fit very well in the context, but, the speakers prefer to use something that grammar defines as barbarisms. Some of the English words float the correct Romanian equivalent as it intends to preserve the full English structure. So, if in English 'to make sense' is a perfectly correct structure, in Romanian 'a face sens' is a mere mot-à-mot translation of the English counterpart, but Romanian has got the verbal expression 'a avea sens' which is the equivalent of the English 'to make sense'. 'Să forcastăm' is an unnecessary barbarism that could have been easily replaced by 'să prognozăm' which will have been enough to cover the meaning of the English word 'to forecast', which, though more powerful in terms of meaning to the Romanian corporate worker, has a perfectly acceptable counterpart in Romanian. The pipeline actually refers to the already existing flow which again has an equivalent in Romanian in 'flux'. 'Customizăm' is but another barbarism which does not bring any new nuance, different from the Romanian one, to the message which strengthens the fact that the products should be 'personalized' to the client, for which, again, Romanian has the equivalent 'a personaliza. The end-user is preferred in this corporate discourse given the target audience that is permanently surrounded by a technicalized, English-impregnated Romanian that has been loaded with gratuitous words that Romanian has and that could perfectly cover the meaning. 'Utilizatorul final' is the equivalent that would satisfy the intended meaning of the speaker. In conclusion, this serves as an example of the fact that transfer between languages exists and it equally indicates that transfer may appear as a necessity (when the speaker uses a structure in mother tongue as the equivalent in L2 is unknown) or as a gratuitous fact (when the speaker retorts to L2, for example, though L1 has the linguistic means to express the same concept).

Another element characteristic of the cognitive approach is the fact that what should be studied is not the linguistic norm and how it is observed, but how the speaker construes the observance and application of the rule, which, when analyzing important groups of respondents, might indicate how users relate to language, be it L1 or L2. Thus, Waara (2004, p. 53) created the concept of 'learner constructions' which are constructions that are 'slightly unconventional'. "Although usage does not result in a communication breakdown between participants, it deviates in some way." The relevance of the 'learner constructions' 
concept to the transfer between L1 and L2 consists of the fact that L2 learners produce L2 structures where they may not comply completely with L2 rules. They may equally fall back on L1 rules which happen to be handier and better known to the learner. Nevertheless, their L2 message gets through despite the contextual inappropriateness or the grammatical errors that may appear.

Other researchers have tried to identify the elements that make the acquisition of L2 difficult, on the one hand, and likely to create interference, on the other. Thus, Larsen-Freeman (1976, p. 128) claims that the order of acquisition of grammatical functors is an element that may create interference between L1 and L2 given the fact that they are empty of lexical meaning and they may have similar forms that will have learners confused. For example, the ' $s$ ' functor is a marker for plural as in $d o g-d o g s$, it is also a marker for the third person singular as in s/he draws and it equally marks the synthetic genitive in English as in butcher's house. All these situations may pose problems to learners of English and consequently they may use knowledge from their maternal language as a support for difficult grammatical choices to make. This corroborated with Matessa \& Anderson's claim (2000, p. 273) that beginners learn L2s by focusing on 'one cue' at a time shows that learning any $\mathrm{L} 2$ is a difficult process which presupposes a gradual exposure to cues, which will lead, in the end, to a reduction of the errors that appear because of misunderstandings or of transfer.

\section{Linguistic transfer in translation}

In writing or speech, L1, better equipped and easier to use, will transfer linguistic elements in L2 which will lead to errors. Yet, linguistic transfer occurs in translating because translating presupposes the rendering of the meaning of a text from L1 into L2. Yet, meaning is expressed by vocabulary, morphology, syntax, pragmatics that may happen to differ more or less between L1 and L2, which means that, sometimes, equivalent structures or approximations are used for elements missing in either of the languages. Havlaskova (2010) describes interference in translation as "a phenomenon that may occur at the level of a word, a phrase, an idiom, a metaphor or a term of a whole syntactic structure when translators transfer some source texts into target texts influenced by aspects of the source language". Benson (2002, p. 69) alleges that such transfers may happen at the level of the syntax as in the case of a word-for-word translation and the failure to use correctly the sequence of tenses, at the lexical level as in the case of false cognates as well as in morphology where different aspects in L1 morphology will be transferred in L2 (the absence of the subject, the failure to recognize the aspects). Moreover, Benson (2002, p. 70) claims that translation of both 'sentences' and 'whole texts' should be encouraged as it illustrates 'specific points' and anticipates 'particular transfer errors'.

\subsection{A description of the aim of the research}

In order to check interference between L1 (Romanian in this case) and L2 (English), I have selected a number of sentences which contain enough differences, when compared, so that students may actually transfer language knowledge from L1 into L2. The confirmation of the interference between Romanian and English in this particular case would, on one hand, confirm the already known theory of linguistic interference, and, on the other hand, it would represent a further reason to encourage teachers to teach L2s by comparing them to $\mathrm{L} 1 \mathrm{~s}$, to resume working on translation exercises which have been mostly abandoned with the advent of the communicative approach to teaching. Thirdly, teachers, given their experience, should predict the elements that are likely to interfere in L2s and should be equally ready to explain to students the elements that trigger the inference errors they have made. Error clarification would help students understand languages as functioning organisms and learning as a progressive undertaking where knowledge, when defective in L2, will encourage students to get back to L1 mechanisms to find a solution.

The activity that the students were supposed to undergo consisted of a number of six sentences which they were asked to translate. The sentences were not long, they were short and simple as they were aimed at certain linguistic elements (morphological, syntactical or lexical) that were likely to lead to either negative or positive transfer between Romanian and English. Markedly, the sentences contained elements which 
were different in Romanian from English and supposedly students might make errors by using their Romanian knowledge when translating into English.

\subsection{Group}

The students participating in this piece of research are first year engineering students who chose English as their foreign language without any formal English test taken upon admission. They are a heterogeneous group with mixed abilities and levels of English, ranging from total beginners to advanced users of English. They took part in this research voluntarily. Those who would not participate in the research worked on the same material, but their papers were not collected for analysis.

\subsection{Morphological interference}

Students' translations brought along a number of situations that were previously intuited by the teacher. One such situation is represented by the impersonal constructions in Romanian which do not have a subject as it is possible in Romanian to use a predicate without a subject given the verbal personal inflections. Yet, this characteristic is absent in English where the absence of inflections led to a compulsory presence of the subject, which some of the students ignored completely. Surprisingly enough, the same situation happens in the case of the personal verb in the same sentence which, because of the same reason, does not have a subject present in the sentence.

(1) [inexistent subject in Romanian, impersonal verbal expression] Ø Nu este politicos să te uiți la oameni cînd (2) [absent subject in Romanian, the subject can actually be deduced from the verbal inflections] $\emptyset$ mănîncă.
The inexistence of the subject in (1) and (2) is preserved in English as students do not realize that they should switch to the English morphological rules when translating into English.

* (1) Is not polite to look at people when (2) eat. $\sqrt{ }(1)$ It is not polite to look at people when (2) they eat.

Another error that appeared in students' translations is connected to the verbal systems of Romanian and English. First of all, there is not a one-to-one correspondence between the Romanian and the English tenses and, moreover, they do not refer to the same situations, which poses extra pressure on the Romanian students. Secondly, although adverbs do signal the moment of the action in Romanian, it's not the adverb the one that imposes the selection of one or another tense or aspect. In Romanian, the adverbs double the temporal information contained in the verb, whereas in English, the adverb, in most cases, asks for a particular tense. The sentences in this case were selected in such a way as to test exactly the above mentioned differences and students' responses to them.

In Romanian, there is only one present tense as Romanian does not distinguish between a permanent situation, a momentary one or an action which has occurred recently. For all these situations Romanian has got only one present. The intermediary space between present and past is completely unfamiliar to Romanian students who may face difficulties as they need to use Present Perfect for two different tenses in Romanian as in 'își face bagajele' (has been packing) because of 'since this morning' and ' $n$ a terminat' (hasn't finished) because of 'yet'.
In English, it is mainly the adverb, though it is not limited to it, the one that dictates the choice of both tense and aspect. Aspect is the grammatical category that establishes if the action is finished or ongoing as this majorly contributes to the complete comprehension of the action. When translating into English, the Romanian students fail to identify the tense as it does not exist in Romanian, but some of them manage to identify the continuous aspect. They miss entirely the decisive contribution of the adverbs 'since this morning', 'yet' to the selection of the tense and establish an equivalence between the Romanian and English verbal system. 
Sora mea îşi face bagajele (1) [it is a present reflexive verbal phrase] de azi dimineață (2) [the presence of the adverb does not change the tense to be used, it only strengthens the present value of the verb], darincă $n$-a terminat (3) [although in Romanian the form of the verb indicates a finished action, in English, thanks to 'yet' Present Perfect Simple is preferred.]
* e.g. My sister is packing since this morning and she didn't finish yet

$\sqrt{ }$ e.g. My sister has been packing since this morning and she hasn't finished yet

Although Romanian has the grammatical notion of aspect, it basically encapsulates the concepts of [unfinished/ ongoing action] as in the case of 'Imperfect' e.g. dansa (s/he was dancing), vorbea (s/he was talking), minca (s/he was eating), [terminat] as in the case of 'Perfect Compus' e.g. a dansat (s/he danced), a vorbit (s/he talked), a mincat (s/he ate) and [finished before another action] as in 'Mai Mult ca Perfectul' e.g. dansase ( $\mathrm{s} /$ he had danced), vorbise ( $\mathrm{s} /$ he had talked), mincase ( $\mathrm{s} /$ he had eaten). Yet, in English aspects are far more complex than this, and it is exactly where errors are likely to appear as Romanian does not cover all the situations that English does.

Romanian does not distinguish between a momentary present and a permanent present as English does. That is why when confronted to such a situation the Romanian students are likely to make errors.

e.g. Bărbatul care (1) vorbește [momentary present] cu soția mea este vecinul nostru care (2) locuiește [permanent present] alături.
The absence of the distinction between [momentary] and [permanent] would lead to errors in the translation of the third action which refers to a permanent state that Romanian students would translate as a momentary state.

* The man who is talking to my wife is our neighbour who is living next door.

$\sqrt{ }$ The man who is talking to my wife is our neighbour who lives next door.

\subsection{Syntactic interference}

When it comes to syntax, there are many differences between Romanian and English, but, there is one which particularly confuses Romanian learners and that is the sequence of tenses. This rule indicates that the verb in the main clause establishes the reference times and that all subsequent times, such as event times, relate to the tense of the verb in the main clause. As there is not such a restriction in Romanian, Romanian learners have a hard time getting familiar to the concepts of simultaneity, anteriority and posteriority and to their application. Given that Romanian accepts Future after Past Tense, Romanian learners will tend to use what Romanian accepts. Another source of errors that Romanian learners confront with is that anteriority is not always clearly marked, which makes learners think that the two actions are simultaneous.

The existence of the two verbs having the same form 'ne-am mutat' and 'am locuit' is mistakenly interpreted as being simultaneous and Past Tense Simple is used to translate the verbs. The anteriority of the action of living for ten years in a house by reference to last week is completely disregarded.

Săptămîna trecută (1) ne-am mutat [past finished action] din casa în care (2) [past finished action] am locuit 10 ani.
The absence of the concepts in the grammar of their mother tongues and the translation of the sentence without any attempt at using the rules of whatever $\mathrm{L} 2$ is being learnt are significant indicators of the differences between L1 and L2. ${ }^{*}$ Last week we moved from the house where we lived for 10 years.

$\sqrt{ }$ Last week we moved from the house where we had lived for 10 years. 


\subsection{Lexical interference}

False friends, as defined by the Cambridge Dictionary, "are words that are often confused with other words in other languages with different meanings because they look or sound similar". Learners rely heavily on words that look like native words as that would confer them a wider choice of vocabulary when in need. Romanian learners are no exception and they use the English verb "to declare" for the Romanian "a declara”.

The sentence "Vă declar soț și soție" is a formula that is used whenever a new couple gets married. The translation of 'a declara' by 'to declare' which is only one letter different is a regular trap for the students that do not use English frequently and do not take a special interest in learning it.
The Cambridge Dictionary defines "to declare" as "to announce something clearly, firmly, publicly, or officially" which is different from the English ceremonious formula that is traditionally used when getting married "I pronounce you man and wife". Moreover, the students copy the Romanian model and they translate "soț și soție" as "husband and wife" which is different from the set phrase "man and wife".

\section{Solutions to linguistic transfer}

Linguistic transfer has been blamed for many types of mistakes that learners of L2s make as a result of the phonetic, lexical, morphologic, syntactic and pragmatic differences between L1 and L2. Learners transform their mother tongue in a reference point against which the imput in L2 is compared. Any errors that ensue from here reflect the learners' need to rely on something sure when learning something new or difficult.

As linguistic transfer has been considered 'natural' by linguists, then it should be taken into account by teachers who should state clearly its existence in the teaching process and take advantage of it if there are any compatibilities between the students' L1 and L2 (Pavel, 2019, p. 6029). Students should be told about the compatibility or lack of it between their L1 and L2 by means of contrastive analysis that should be incorporated into the teaching/ learning process as they should be aware of the similarities and dissimilarities between languages as a factor that can contribute to either their correct learning of L2 or their likelihood of making mistakes in L2 due to L1 differences from L2. Therefore, teachers should emphasize the characteristics proper to each and every language and raise students' awareness of language-specific features that may create difficulties when translating from L1 into L2. Moreover, teachers should get students involved in identifying transfer situations by devising contexts where students have to distinguish between the right/ wrong choice which may result from either positive or negative transfer. Or, teachers could ask students to create contexts where to use either positive or negative transfer situations because, in this way, students show comprehension of the phenomenon and they can see exactly how transfer functions.

\section{Conclusions}

The aim of this piece of research has been to check the existence of the linguistic interference between the Romanian students' L1 and English as their L2 when working on some translation sentences from Romanian into English. The sentences were chosen on purpose so as to contain flagrant differences between Romanian and English in order to check if the Romanian students participating in the study will transfer Romanian structures from Romanian into English, or, on the contrary, they will use the English structures. The transfer of Romanian structures into English will demonstrate that the students participating in the research were not independent users of English able to apply awaringly the English structures. On the contrary, the absence of or a reduced transfer between L1 and L2 would indicate that transfer does not take 
place because the participant students have reached a level of mastery of English that allows them to rely solely on the English structures. In relation to this, the research has demonstrated that these participants rely heavily on Romanian when translating into English which means that when dealing with English they have not separated from Romanian which they use as an important support.

Secondly, any linguistic transfer is a normal way of dealing with new information, which may be an explanation of why students need to rely on something they are very familiar with. It should be understood as a mechanism of protection since learning means adjusting the rules to one's understanding of the language, processing of the new information and practicing it more or less successfully. When the transfer between L1 and L2 is positive, the consequence is an easy learning process which results in learnt output. When the transfer between L1 and L2 is negative, the consequence is a difficult learning process which may lead to errors that need further clarification.

Thirdly, translation exercises are complex activities which might bring along numerous transfers of structures between L1 and L2. Though translations have been discouraged, maybe because the Communicative Approach has tried to avoid exactly the difficulties that appear due to the differences between L1 and L2, translations increase, I consider, the learner's awareness of the linguistic features of each language, which might help form informed speakers of foreign languages instead of speakers who are excused the troubles of discovering that languages do differ and that it is the difference that stimulates learning.

Lastly, it is not recommended to tell students to stop relying on their L1 because they will not give up on the only resource available. Moreover, it is teachers' role to foresee what might lead to negative transfer and try to instruct students how to deal with them. Still, positive transfer is extremely valuable and it should be exploited awaringly by both teacher and students because it enhances students' interest, motivation and progress.

\section{Bibliography}

Achard, M. \& Niemeier, S. (2004). Cognitive Linguistics, Second Language Acquisition, and Foreign Language, Mouton de Gruyter, Berlin, Crossref.

Benson, C. (2002). Transfer/Cross-linguistic influence. Key concepts in ELT, Oxford University Press, Oxford.

Cooter, R.B. \& Reutzel, D. R. (2004). Teaching children to read: Putting the pieces together, Pearson Education, Inc., Upper Sadle River, NJ.

Corder, S.P. (1967). The significance of learnerserrors, in "International Review of Applied Linguistics", 5 (1-4), p. 161-169, Crossref.

Ellis, R. (1997). The Study of Second Language Acquisition, Oxford University Press, Oxford.

Ellis, R. (1998). Second Language Acquisition, Oxford University Press, Oxford.

Fauconnier, G. (1997). Mappings in Thought and Language, Cambridge University Press, Cambridge, Crossref.

Havlaskova, Z. (2010). Interference in students' translation, Masaryk University, Brno.

Jozefowiez J. (2012). Associative Learning, in Seel, N. M. (ed.), Encyclopedia of the Sciences of Learning, Springer, Boston, MA, Crossref.

Lado, R. (1957). Linguistics across Cultures: Applied Linguistics for Language Teachers, University of Michigan Press, Ann Arbor.

Langacker, R. (2008). The relevance of Cognitive Grammar for language pedagogy, in de Knop, S. \& de Rycker, T. (eds), Cognitive Approaches to Pedagogical Grammar, Mouton de Gruyter, Berlin.

Larsen-Freeman, D. (1976). An Explanation for the Morpheme Acquisition Order of Second Language Learners, in "Language Learning", 26 (1), p. 125-134, Crossref.

Lord, G. (2008). Second language acquisition and first languagephonological modification, in Bruhn de Garavito, J. \& Valenzuela, E. (eds), Proceedings of the 10th Hispanic linguistics symposium, Cascadilla proceedings project, Somerville, MA, p. 184-193, [online].

Matessa, M. \& Anderson, J.R. (2000). Modelling focused learning in role assignment, in "Language and Cognitive Processes", 15 (3), p. 263-292, Crossref.

Pavel, E. (2019). English for Medical Purposes: From Errors to Alternative Pedagogical Solutions, in "ICERI2019 Proceedings", p. 6029-6035, Crossref.

Schmidt, J.R. (2012). Human Contingency Learning, in Seel, N.M. (ed.), Encyclopedia of the Sciences of Learning, Springer, Boston, MA, Crossref.

Storch N. \& Wigglesworth, G. (2003). Is there a Role for the Use of the L1 in an L2 Setting?, in "TESOL Quarterly", 37 (4), p. 760-770, Crossref. 
Swan, M. (1985). A critical look at the Communicative Approach (2), in "ELT Journal", 39 (2), p. 76-87, Crossref.

Waara, R. (2004). Construal, Convention and Constructions in L2 Speech, in Achard, M. \& Niemeier, S. (eds), Cognitive Linguistics, Second Language Acquisition, and Foreign Language, Mouton de Gruyter, Berlin, p. 51-76, Crossref.

Weinreich, U. (1953). Languages in contact, Linguistic Circle of New York, New York.

Yadav, M. (2014). The Role of Mother Tongue in Second Language Learning, in "International Journal of Research", 1 (11), p. 572-582, [online]. 